See Article page 1104 .

\section{Commentary: Details and concentration}

\author{
William L. Holman, MD, Robert A. Sorabella, MD, \\ and James E. Davies, MD
}

The infamous bank robber Willie Sutton (1901-1980) once said, "Success in any endeavor requires single-minded attention to detail and total concentration." Cardiac surgery is different from armed robbery, but the need for attention to detail and concentration is no less. One important detail of any cardiac operation is management of the heart during the crossclamp interval.

Pedro del Nido and associates developed a cardioplegia (CP) solution intended for infants and children (del Nido solution [DNS]). ${ }^{2}$ In this issue of the Journal, Waterford and $\mathrm{Ad}^{3}$ have written an expert opinion for surgeons using DNS in adults. Ad previously published a prospective randomized trial of DNS versus whole blood CP. ${ }^{4}$ It is worth reading as background, as is the commentary by Lazar. ${ }^{5}$

It is fair to say that DNS is here to stay. ${ }^{5}$ The sustained arrest (ie, electromechanical quiescence) produced by DNS decreases the need for maintenance doses of $\mathrm{CP}$, which in some instances requires rearranging exposure and interrupting the flow of the procedure. Topical cooling is performed as usual with DNS; however, the duration of uninterrupted ischemia is increased when maintenance doses of CP are not given. None of these considerations matter much with a clamp time less than 90 to 120 minutes, but they become increasingly important with longer clamp times or in hearts with advanced pathology (eg, myocardial fibrosis, hypertrophy, severe coronary atherosclerosis). There is little secure information on the relative merits of DNS versus other CP solutions in adults, so it is up to the

\footnotetext{
From the Division of Cardiothoracic Surgery, University of Alabama at Birmingham, Birmingham, Ala.

Disclosures: Dr Holman serves on DSMBs for Medtronic and Abbott. Dr Davies serves as a consultant to Edwards and Medtronic. Dr Sorabella reported no conflicts of interest.

The Journal policy requires editors and reviewers to disclose conflicts of interest and to decline handling or reviewing manuscripts for which they may have a conflict of interest. The editors and reviewers of this article have no conflicts of interest.

Received for publication Nov 26, 2021; revisions received Nov 26, 2021; accepted for publication Nov 30, 2021; available ahead of print Dec 4, 2021.

Address for reprints: William L. Holman, MD, Division of Cardiothoracic Surgery, University of Alabama at Birmingham, 703 19th St South, Room 719, Birming-

ham, AL 35294 (E-mail: wlholman@uabmc.edu).

J Thorac Cardiovasc Surg 2023;165:1109-10

$0022-5223 / \$ 36.00$

Copyright (c) 2021 by The American Association for Thoracic Surgery

https://doi.org/10.1016/j.jtcvs.2021.11.071
}

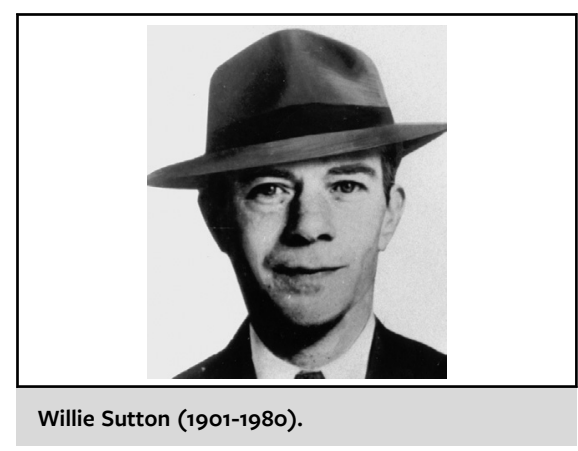

$$
\begin{aligned}
& \text { CENTRAL MESSAGE } \\
& \text { Waterford and Ad provide an } \\
& \text { expert opinion regarding del } \\
& \text { Nido cardioplegia solution (DNS) } \\
& \text { used in adults. Time will tell } \\
& \text { whether DNS becomes domi- } \\
& \text { nant or remains just another } \\
& \text { acceptable alternative. }
\end{aligned}
$$

surgeon to be knowledgeable about the myocardial management technique chosen for each patient and to ensure that every detail is handled properly.

Waterford and Ad pose questions and answers that are important to consider when using DNS. Perhaps the most important is regarding maintenance doses (redosing) of $\mathrm{CP}$ during long ( $>60$ - to 90-minute) crossclamp times, assuming that electromechanical quiescence is maintained. What volume (dose) should be given and should a different CP solution than DNS be used for redosing? Who is responsible for monitoring the total dose of lidocaine that is administered? Should DNS be used for all adult cases or just cases that have risk factors for adverse outcomes (eg, cardiomegaly with poor contractility; expected long crossclamp time)? How important is it to employ topical cooling when using DNS? Is it safe to give DNS with a retrograde technique, especially if a larger dose of DNS is necessary to achieve and maintain arrest?

Communication among the team (surgeon, anesthesiologist, perfusionist, and nurse) is crucial when changing techniques for myocardial protection. Moreover, the protocols that the team develops must be adhered to and iteratively evaluated to be sure that the best outcomes are achieved.

Finally, it is interesting to review the statistical methodology from Ad's 2018 study. ${ }^{4}$ It began as a noninferiority analysis. However, after "meaningful differences beyond 
non-inferiority were found," it was changed to a superiority analysis. Time will tell whether DNS becomes dominant or remains just another acceptable alternative.

\section{References}

1. Quote from Willie Sutton. Accessed November 23, 2021. https://www.azquotes. com/quote/873298
2. Matte GS, del Nido PJ. History and use of del Nido cardioplegia solution at Boston Children's Hospital. J Extra Corpor Technol. 2012;44:98-103.

3. Waterford SD, Ad N. Del Nido cardioplegia: questions and (some) answers. $J$ Thorac Cardiovasc Surg. 2023;165:1104-8.

4. Ad N, Holmes SD, Massimiano PS, Rongione AJ, Fornaresio LM, Fitzgerald D. The use of del Nido cardioplegia in adult cardiac surgery: a prospective randomized trial. J Thorac Cardiovasc Surg. 2018;155:1011-8.

5. Lazar HL. Del Nido cardioplegia: passing fad or here to stay? J Thorac Cardiovasc Surg. 2018;155:1009-10. 